\title{
A Historical View of Context
}

\author{
MATTHEW CHALMERS \\ Computing Science, University of Glasgow, Glasgow, G12 8QQ, United Kingdom
}

\begin{abstract}
This paper re-examines a number of the approaches, origins and ideals of context-aware systems design, looking particularly at the way that the past influences what we do in our ongoing activity. As a number of sociologists and philosophers have pointed out, past social interaction, as well as past use of the heterogeneous mix of media, tools and artifacts that we use in our everyday activity, influence our ongoing interaction with the people and media at hand. We suggest that the past is thus part of one's current context, and can be seen as combining and interweaving the temporal and subjective patterns of individuals' use of heterogeneous media as well as objectively structured representations of individual media. Based on this theoretical discussion, we present a number of critiques, examples and suggestions for systems designs that reflect this historical aspect of context, and which make good use of the past in supporting ongoing user activity.
\end{abstract}

\section{Introduction}

Context and awareness are at the core of both CSCW and context-aware computing, albeit with different interpretations with regard to theoretical principles and design practice. An extreme view, deliberately highlighting differences, might hold them as incompatible or conflicting: CSCW focuses on intersubjective aspects of context, constructed in and through the dynamic of each individual's social interaction, and defends against reductionism and objectification. In contrast, context-aware and ubiquitous computing often concentrate on computational representations of context that span and combine many senses and media-rather than the social construction of context in interaction. In the introductory article of a recent special journal issue on context-aware systems, Dey et al. describe context as "typically the location, identity and state of people, groups and computational and physical objects" (Dey et al., 2001). Such definitions are common in context-aware and ubiquitous computing, but they do tend to emphasise objective features that can be tracked and recorded relatively easily, and to de-emphasize or avoid aspects of the user experience such as subjectively perceived features and the way past experience of similar contexts may influence current activity - issues which are central concerns of CSCW. However, as this special journal issue exemplifies, both fields increasingly recognise the need for bridging or even synthesis.

This kind of discussion and this kind of dichotomy have appeared before in HCI and $\mathrm{CSCW}$, and it would seem appropriate to draw from that experience here. There 
is a long-standing discourse on the conflict between the infinite and subjective detail of social interaction, and the finite and objective aspects of systems design. One key issue has been how systems can represent work and its context without over-formalising, over-simplifying and over-objectifying it. A canonical example in CSCW is the attempt by Winograd and Flores to make theoretical discussion and system design inform each other in the workflow design approach, as implemented in a system called The Coordinator (Winograd 1986). The Coordinator was essentially an email tool in which the system supported one's work not only by presenting the content of each document for editing, but by presenting the document's context within a flow or temporal pattern of social interactions, such as a request from someone for its creation and the promise to deliver it to someone else once complete. Workflows were thus 'conversations for action' built from a pre-designed categorization of work interactions. The system gave users an explicit representation of the process of work as well as the documents, spreadsheets, reports and other artifacts handled and constructed within the work process.

Winograd and Flores drew on a number of experiences and theories, but central among these was the work of the philosopher Martin Heidegger (Heidegger 1927/1962, Grondin 1994). In particular they focused on Heidegger's phenomenology and ontology, in which human activity is treated as an ongoing temporal process of language and interpretation, rather than a series of separable perceptions, each of which frames and fixes the world as a set of symbols or signs. $\mathrm{He}$ (and they) treated language as activity, and activity as language, i.e. language was seen not merely as a mode of representing things, but as a mode of doing things. By formalizing and making explicit the temporal flow of such actions, Winograd and Flores aimed to make work 'present-at-hand', in that people in an organisation would use the workflow as a way to consciously focus on their work, rationalising it and making it more efficient.

Such workflow-like representations of activity are being brought into context-aware computing. In Activity-Based Computing, (Christensen 2002; Bardram 2003), a direct connection is made between context-aware systems design and the formal models of activity in workflow and Activity Theory (Nardi 1996). In their healthcare systems for hospitals, patient treatment is organized and managed through a set of defined tasks or activities that have been decided upon by all clinicians. Each clinician's work activity is represented as a heterogeneous collection of computational services, and such services are made available on various stationary and mobile computing devices. A related system design approach is the 'task driven computing' approach of the Aura system (Garlan, 2002), in which tasks are 'explicit representations of user intent' constructed out of 'coalitions of abstract services' within the system.

However, such representations of activity have a potential danger, namely "that their design is predicated entirely by formal procedures-ignoring (and even 
damaging) the informal practice" (Bardram 1997), and this leads to a paradox or tension that Bardram summarises well:

On the one hand, due to the contingencies of the concrete work situation, work has an ad hoc nature. Plans are not the generative mechanisms of work, but are 'merely' used to reflect on work, before or after. On the other hand, we find that plans, as more or less formal representations, play a fundamental role in almost any organisation by giving order to work and thereby they effectively help getting the work done.

Such pre-designed formal categorizations and representations of work can be useful as resources for action, and as resources for accounting for one's action, but tightly structured representations of work raise concerns in CSCW. A good proportion of mainstream CSCW researchers have focused on revealing the same detail of socially-constructed situated action that is excluded from these representations. It may be expected that a context-aware system's task models will be examined to show whether they are designed with the intention or assumption of being carried out with script-like consistency, instead of being seen as flexible map-like resources for the situated action of users (Suchman 1986), how much work is needed to make their use fit with the use of other work media, beyond the workflow system, that may not be easily tracked or controlled by the system (Bowers 1995), and whether they fully represent the dynamics, detail and articulation of users' intents and priorities (Schmidt 1997, Bannon1997).

A contrasting approach to combining CSCW and context-aware systems emphasises socially-constructed situated action, and is also inspired by some of the foundational work of ubiquitous computing. The embodied interaction perspective on HCI (Dourish 2001) binds together CSCW and context-aware computing issues in presenting everyday human interaction as non-rationalising, intersubjective and bodily activity. It treats interaction and context as dynamic achievements of the people involved, and as involving the wide range of media and senses that are involved in their bodily activity. It draws upon sociology, especially the ethnomethodology of (Garfinkel 1967), and upon philosophy, in particular phenomenology. The use of the word embodiment stems from (Merleau-Ponty 1945/2002), and Garfinkel drew heavily from (Schutz 1932/1967).

Where The Action Is makes it clear that embodiment is an issue to address in design practice, but does not provide specific practical design guidelines, offering instead statements that help sensitise designers to general issues. Two key examples are users, not designers, create and communicate meaning and users, not designers, manage coupling, where 'coupling' refers to the process or activity of contextualisation i.e. fitting an object or reference into the non-rationalising, intersubjective and bodily activity that makes up a person's everyday life. More recently, however, Dourish applied this embodied interaction perspective to the notion of context and context-awareness more practically (Dourish 2004). This paper focuses on a question highly relevant to our focus here: "how can sensor technologies allow computational systems to be sensitive to the settings in which 
they are used, so that, as we move from one physical or social setting to another, our computational devices can be attuned to these variations?"

The key distinction or dichotomy he puts forward is between physical or positivist notions of context, which centre on objective representation of social and interactional phenomena, and social or phenomenological notions of context, which centre of a view of context as a subjective and situated aspect of people's interaction. He points out that the design practice of context-aware and ubiquitous computing is in objective or positivist notions of context, even though its ideals are bound up with social and phenomenological notions. Dourish refers to the Weiser's Scientific American article (Weiser 1991), which uses the work of social anthropologists such as Lucy Suchman and Jean Lave, and philosophers such as Martin Heidegger and Hans-Georg Gadamer. Similarly, he refers to (Abowd 2002), which cites activity theory, situated action and distributed cognition and ethnographic studies as important resources for ubiquitous computing. He suggests that the field's ideals of combining the social and the technical have not yet been achieved: "turning social observation into technical design seems to be problematic" and "these two positions are incompatible".

The paper puts forward an interactional view of context based on the embodied interaction perspective, most particularly ethnomethodology, and uses this view to offer three system design principles. These are intended to allow forms of practice to emerge and evolve, rather than requiring users to fit their work and their information to predefined patterns. Firstly, systems should display their own internal state and configuration to users, so as to allow the user "to make continual determinations of the potential consequences of their actions and their opportunities to reconfigure or realign the technologies through which they are conducting their actions". Second, deep system structure should be revealed so as to support system inspection and adaptation, i.e. the system's internal structure becomes a resource for the work of adaptation and contextualisation. Third, interfaces should offer "direct experience of the structures by which information is organized", e.g. in spatial hypertext structures, viz. "Structure emerges in the course of a user's interaction, rather than having to be specified all at once or in advance of the actual data being incorporated."

These design principles seem to head in a useful direction, but there are difficulties to face. Opening up the deep structure of the implementation means designing a presentation or account of system structure and behaviour that is comprehensible and manipulable by users. Presumably we cannot reveal every detail of the entire system all the time, and so we will have to be selective and, to some extent, reductive with regard to the features and processes we open up. The adaptation mentioned in the second principle may be a means to make this selection and reduction a dynamically changing choice, rather than a design choice made $a$ priori, but a system design would have to address the finite experience and 
understanding of the individual user, with regard to system structure, possibilities for reconfiguration, and potential consequences. A 2D information space may offer advantages of overview of information structure, and serve as a workspace for people to negotiate and articulate changes to the system, but the issue of how to graphically present and interact with the system seems very challenging given the complexity of current structure and of current use, and the openness for new configurations, uses and interpretations. The system has to do more than 'find structures that are visually salient to users, such as clusters, piles, columns, tables, etc.', which rather begs the question: clusters and tables of what? The users have to find structures that are salient to the context, with all the dynamism, subjectivity and openness that Dourish correctly points out to be key characteristics of context. As we will return to later, it also may appear strange that Dourish is proposing fairly explicit and conscious use of the system here, which rather clashes with the ideals of embodied interaction and the 'invisibility' of the tool promoted in embodied interaction and ubiquitous computing.

These design principles may be challenging to the designer, but the challenge facing the users is perhaps greater if indeed structure only emerges in the course of a user's interaction, and if the 'achievement' of context and activity is as isolated and subjective a choice as suggested by the sociology and phenomenology presented here. We suggest, however, there seem to be aspects of interaction and context that this view and these principles do not address. There are influences and constraints on the meaning and use of a system design, beyond or prior to the person or people in the situation or occasion of use i.e. from within the design and without.

We suggest that it seems too narrow to say that users, not designers, create and communicate meaning and or to claim that users, not designers, manage coupling and contextualization. Even if designers do not predetermine the meaning, coupling or contextualization of a design, they do influence and constrain it. They cannot avoid doing so, because any computer system that affords representation and awareness of human activity necessarily involves a degree of reduction and objectification, due to the formal representational schemes of programs and databases, and finite capacities for storage, communication and calculation. Any digital system is finite and physical, with limits what it can record of people's activity, what it can represent internally, what mechanisms of adaptation are encoded in those internal representations, and what external representations such as output devices it can use. Any design makes manifest designers' implicit and explicit assumptions with regard to how to reduce, formalise or objectify context and activity i.e. the choice for the system designer is not whether to reduce, objectify or constrain users' context, but how (Chalmers 2003). The designer cannot predetermine users' activities, meanings and interpretations, but also cannot be uninvolved. The designer has no choice but to influence the meaning that users 
make, and cannot avoid influencing the ways that they manage coupling and contextualization.

While we gain from understanding the detail of context and social interaction, and aiming for consistency with strong and well-founded theory, we must take a pragmatic stance if we are to design the finite and formal representations that constitute context-aware and CSCW systems. Embodied interaction is a good exemplar of research in CSCW and context-aware computing that begins to bridge between useful practice and strong theory, but it seems that there are still difficulties and limitations to address. In the following sections, we focus on the theoretical ideal or ideals for ubiquitous and context-aware computing that Dourish, Weiser and Abowd et al. present, aiming to reassess it in terms of its strengths, weaknesses and alternatives as theory 'in itself', and in terms of how such theory reflects or drives design practice. In each section, we use theoretical discussion to critique some aspects and examples of recent design practice, and to propose some new ones.

\section{The Past as Part of Context}

The view of context that holds sway in CSCW, and is exemplified in the work of Dourish but also in the writings of Weiser, is rooted in texts such as Studies in Ethnomethodology (Garfinkel 1967) and Plans and Situated Actions (Suchman 1987). These are primary texts for CSCW's user studies and system critiques. Ethnomethodology itself has roots in the phenomenology of Schutz, which, in turn, built on Heidegger's hermeneutic phenomenology and the later philosophy of Wittgenstein (Wittgenstein 1958). Heidegger may be one of the most influential yet least recognized influences on $\mathrm{CSCW}$, context-aware and ubiquitous computing. The centrality of Heidegger to Weiser's work is hinted at by the first lines of Weiser's Scientific American article, which used Heidegger's notion of the 'disappearance' or 'invisibility' of a tool or technology-a notion which has become emblematic of the ubiquitous computing approach.

As pointed out above, the extension of such sociology and philosophy into the heart of the design practice of CSCW and context-aware computing has been problematic, despite the intentions of Weiser, Dourish and others. Some possible reasons for this were briefly mentioned earlier in this paper, and here we try to expand on them by looking at critiques and advances made by later sociologists and philosophers. We aim to better understand such theory's strengths, weaknesses and successors. In particular, we focus on understanding which aspects of human activity, knowledge and interpretation such standpoints address, and which they do not, and the apparent dichotomies and paradoxes characteristic of such theory - which we suggest have been at the heart of our field's difficulty in applying theory to system design in both CSCW and context-aware computing. 
Anthony Giddens, one of the leading sociologists of the present day, submitted ethnomethodology to what he called a 'constructive critique' (Giddens, 1995), and this may be useful to us. He points out five distinguishing themes in ethnomethodology: its emphasis on human action or agency, which most of the earlier leading schools of sociology had lacked; the capacity of human agents for self-reflection, which he suggests most orthodox forms of sociology had considered a 'nuisance' but which the philosophers held as integral to human action; language, conceived of not simply as a set of symbols or signs, but as a 'medium of practical activity' i.e. as a mode of doing things and not merely a mode of representing things; the temporal and contextual locating of action within what has been said and done by the actors in a setting or scene, and anticipation of future courses of action; and, finally, tacit or 'taken for granted' understandings drawn upon by actors as ordinary, but unexplicated or non-rationalised, conditions of social interaction. Ethnomethodology's emphasis upon this last theme in is one of its direct points of connection to phenomenology.

Generally speaking, these are theoretical strengths, but Giddens also points out a number of weaknesses in ethnomethodology, only some of which we mention here. The first relates strongly to the issues of who creates meaning, and who manages coupling and contextualization, which were raised in the previous section when discussing the influence of the system designer and the system on use and users. It is ethnomethodology's narrow focus on the moment-by-moment subjective orientation of each human actor in a setting or scene, which tends to ignore or underestimate the influence of others who are not currently present in the scene. A later point takes this issue somewhat further: "ethnomethodological studies are concerned with the production of society, as a skilled accomplishment of lay actors, but much less with its reproduction as a series of structures", for example the act of speaking grammatically as reproducing the rules used to generate the utterance. The influence of the past may be spoken of, or be interpretable in terms of, generalizations such social rules and structures, or in terms of the individual's understanding, memory and experience of interactions with others not currently present. It is not suggested that such temporal or social structures determine (or predetermine) the actions of a person, but rather that these abstractions are ways to understand influences on activity and interpretation-resources or constraints that ethnomethodology underemphasizes.

Social structure is a sensitive topic in sociology and philosophy, as perspectives on the nature and status of structures such as language grammar, organizational hierarchy, and social or economic class are often the key sources of division and discrimination between approaches in these fields. Older approaches often relied on rules, laws and concepts that were believed to determine the lives of the people who were described in terms of those rules, laws and concepts, despite those people being unaware of their existence or influence. Giddens describes these as naïve conceptions, in which structure "appears as 'external' to human action, as a source 
of constraint on the free initiative of the independently constituted subject" (Giddens 1984, p. 16). Instead he proposes that "social systems, as reproduced social practices, do not have 'structures' but rather exhibit 'structural properties' and that structure exists [...] only in its instantiations in such practices and as memory traces orienting the conduct of knowledgeable human agents" (p. 17). This is not to suggest that structure is prior to or contradictory to individuals' situated action. Later in the same book (p. 332), Giddens uses Wilson's account of the 'duality' of structure and situated action (Wilson 1983) as offering an account of this reflexive relationship that he could not better:

"the social world is constituted by situated actions produced in particular concrete situations, that are available to the participants for their own recognition, description, and use as warranted grounds for further inference and action on those same occasions as well as subsequent ones. Situated actions are produced through context-free and context-sensitive mechanisms of social interaction, and social structure is used by members of society to render their actions in particular situations intelligible and coherent. In this process, social structure is an essential resource for and product of situated action, and social structure is reproduced as an objective reality that partially constrains action. It is through this reflexive relation between social structure and situated action that the transparency of display [the mutual intelligibility of conduct] is accomplished by exploiting the context-dependence of meaning"

We can see this duality in more technical terms, as a sort of feedback loop in which the instantiations of social practices as well as memory, experience and understanding influence and partially constrain activity and interpretation. However, ongoing activity and interpretation leads to new memories, extended experience and changed understanding, and reproduction and adaptation of social structure. Thus financial limits, organizational procedures, legal constraints and also material artifacts are both constraints on individuals and resources for individuals. The use and adaptation of tools and artifacts in material form, including digital systems, is influenced by social structures and individual's memories, experiences and understandings, as well as their finite physical or objective properties.

Giddens points out that later forms of phenomenology than the one Garfinkel drew from took fuller account of the way that past experience, including past social interaction and individual reflection and action, influences current interpretation, reflection and action: "'Hermeneutic phenomenology' in the hands of Heidegger and Gadamer breaks with the subjectivism characteristic of the earlier phase of development of phenomenology. (Schutz never managed to complete this break.)" Gidden's description of the duality of structure draws on older concepts such as the 'hermeneutic circle' through which one's current understanding, interpretation and action are influenced by one's past experience, and yet also extend and shape one's experience, and Gadamer's concept of 'historically effected consciousness' (Gadamer 1960/1989, Warnke 1987).

We suggest, therefore, that a key systems design issue to draw from this theoretical discussion is the importance of the past to context and use. In particular, we suggest that past interactions with people and systems, and the structures or 
abstractions over those experiences that are used as resources in people's activity, seem underrepresented in the theory and the practice of context-aware system design. Individuals' experiences of past interactions with others are a manifest influence and resource for their action and interpretation, but are not often made manifest in context-aware systems' models of context.

There are some examples of systems' use of the past, of course. Focusing for the moment on the museum setting, which has been a significant area of application for context-aware systems, HIPPIE adapted the presentation of information in a museum, and presentation of the attributes within the system's database, based on a record of what displays and related information a visitor had seen before, either in the museum or previously (Oppermann 1999). The system of (Schiele 2001) captured video images of paintings in a museum tour, and then would later automatically retrieve video recordings of the tour guide if one later came across the same paintings (or realistic enough reproductions). A rather simpler example was the HP Cooltown Rememberer system, which built up a visit record, consisting of a set of web pages. Users left the museum with an artifact that was intended to remind the user of the visit and which contained a URL for the visit record, for example a fridge magnet with an embedded RFID tag (Fleck 2002).

Taking such systems as representative of the wider area of context-aware systems design for the moment, we suggest that there has been a tendency for context-aware systems' use of the past to focus quite narrowly on the objects and locations used in the past by one person, and not how that person used them in the course of social interaction with friends or colleagues, for example, or how other people used those objects and locations in their interaction. Also, we rarely show or take advantage of the temporal structure of past use, for example the actions and interactions that preceded, co-occurred with and followed each recorded use.

One of the few systems that take advantage of patterns of co-occurrence in use is the 'Smart Its Friends' technique for establishing connections or associations between artifacts (Holmquist 2001), which relied on correspondences in implicit movement to discover associations between subsets of a collection of small devices, such as the objects one usually carries in a shoulder bag or briefcase as one leaves for work, or through explicit shaking. These objects were part of each other's context, or part of the same context, if they were used along with each other, which is a distinctly structuralist approach. It would seem, however, that Holmquist et al. never took the further step of using such patterns as a social resource, building up data on use that would serve as a resource for others as to what devices to combine, where to use them, and what new devices to find out about or obtain.

In our ongoing work on two context-aware systems at U. Glasgow, the George Square system and the Seamful Game, we have tried to make the past a resource in just this social way. The George Square system is designed to aid pairs of tourists during a visit to the city, and is currently undergoing user trials. It runs on a tablet 
PC, and involves several connected tools and devices: GPS, 802.11, a VoIP audio link, a web browser, a small webcam and a 2D display (Figure 1) that centres on a map of the city centre. Each visitor has such a tablet, and sees on his or her map both visitors' locations. A user can present his or her location to the system, and to the other visitor, either implicitly or explicitly, i.e. via GPS, or by dragging his or her own icon across the map. When one visitor takes a photograph, it is shown to both of them. It is shown in a 'filmstrip' at the top of each visitor's display, and in smaller form at the location of the user who took it. One of the influences on George Square's design was a study of tourists in city centres (Brown \& Chalmers 2003), which highlighted the sharing and discussion over maps, guidebooks, accounts and photographs from past visits before, during and after the visit.

The ongoing activity of each individual, in terms of locations, photographs taken and web pages loaded, is logged, forming a history for each user. By using a variant of the Recer recommender system (Chalmers 1998), we use these histories to make recommendations of places to go, photographs to see and web pages to read. Recer finds past periods of activity in the user histories that share the locations and URLs one has used recently, and selects other locations and URLs from these periods as recommendations. The recommendations that a visitor receives are shown on his or her map, and are listed in a panel on the right of the display. He or she is also made aware of the other visitor's recommendations, shown ghosted on the map and in a second list on the right of the display, so that each visitor not only has as a resource individually-tailored selections of the past, but can talk about and compare them with their co-visitor, and fit them into their current activity.

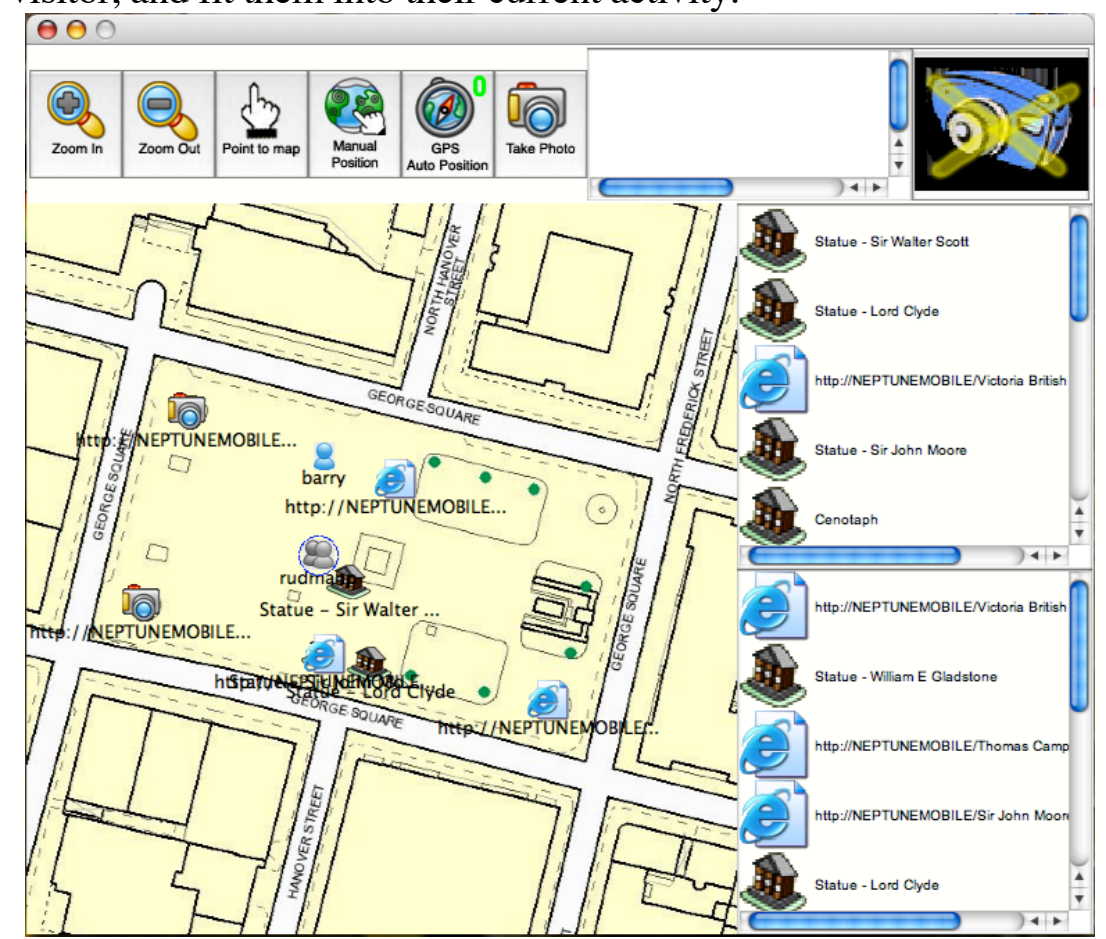

Figure 1: The George Square system offers synchronous awareness of users' locations and photography, and asynchronous awareness of selected past movements, photography and web page use chosen by the Recer recommender system. 
The George Square system also creates a 'blog' from each visitor's activity, which they can use via the web to remind them of their past experience and as a resource for future visits and discussions with others. The blog page shows the temporally-ordered list of locations and URLs from the visitor's log, which he or she can select from and edit. A map tool much like the one used on the tablet during the system trial, also shows a spatial representation of the selected and/or edited log data.

In our ongoing and future work, we intend to take the notion of recommendation somewhat further. Patterns of use can lead to good recommendations for people, but we are interested in exploring whether tracked features such as locations, web page use, GPS availability, network access and so forth can be combined with tracking the use of the components within a system. In this way we hope to address the difficult challenge of adapting deep system structure in the light of socially-constructed patterns of use as well as the objective constraints of component functionality and performance.

Another of our systems that makes the past a resource for the present is the Seamful Game. Outlined in (Chalmers et al., 2003) but now undergoing user trials, this is a game for mobile computers, especially handhelds. It is designed to let users take advantage of the spatial variation in wireless network coverage and GPS positioning. The game centres on 'coins' that appear on a street map on each player's computer.

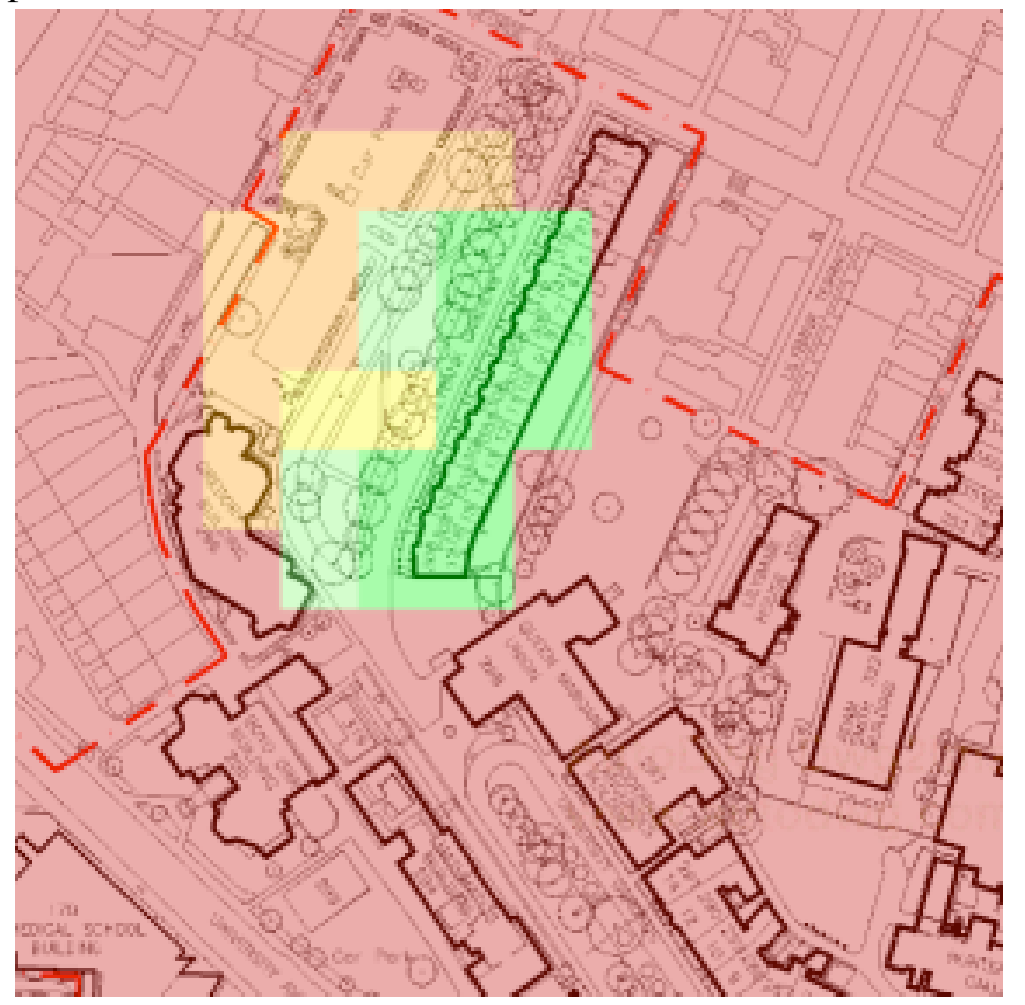

Figure 2: A 'seamful map' of 802.11 signal strength overlays a street map in the Seamful Game. The maps are made from 802.11 and GPS strength data gathered during game play and made available as a resource for later players' system use and game tactics. 
Players have to get close to and pick up in order to gain points. Coins often appear in areas where there is no network coverage, or where GPS positioning is poor, and so players have to know where such infrastructure services-usually assumed to be ubiquitous and seamless - are strong, weak or missing. A player can take tactical advantage of features such as GPS shadows and poor 802.11 coverage, e.g. to avoid or to sneak up on other players. They can also use as a resource the activity of past players: the system periodically samples and $\operatorname{logs} 802.11$ signal strength and the number of GPS satellites, and this data is used to make seamful maps: discretised map overlays that reflect where past individuals have played, and some of the technological resources they used there. An example player's street map with an 802.11 overlay is shown in Figure 2.

We are also considering other uses of the past as a resource for current users' activity, for example as a means to help users who seem to be in difficulty by showing what other people did in similar circumstances. The past can also be a resource for predictive resource management, as in the QoS management system of the MASSIVE CVE system (Greenhalgh 1998) and the web page prefetcher of (Signer 2000).

In summary, we suggest that by looking deeper into the theory in CSCW and $\mathrm{HCI}$, we can better understand the way that the past is a continually adapting resource for ongoing activity. In our system designs, we can respond to this by selectively making the pattern and detail of past activity part of a system user's current context. Echoing Dourish's guidelines, we suggest that there is useful work to be done in making records of the past into useful and practical elements of displays of systems' state and configuration, and tools for system inspection and adaptation, as part of the 'information spaces' used for negotiation and articulation of work and activity.

\section{Objectifying Context}

Another development in hermeneutics was to begin to address the split between objective and subjective. This development means that incompatibility of the positivist and phenomenological perspectives on context may not be as absolute as Dourish suggests. Applying phenomenological ideas to systems design is difficult, as Dourish and Weiser point out, but it seems inappropriate to accept an intractable dichotomy when contemporary philosophy does not see things quite that way.

Speaking metaphorically, the representations, symbols and notations of science are part of language, and are "new boroughs with straight regular streets and uniform houses" set within the larger space of language (Wittgenstein 1958). The key issue here is the way that objectifications are constructed by people within this larger social system, as are other interpretive frameworks. People 'do' objectification, conscious reflection and rationalisation, as well as the 
non-rationalising, intersubjective and bodily activity that makes up much of person's everyday life. Furthermore, objective and subjective are bound together, and are central to Heidegger's concept of the disappearance or invisibility of a tool or technology (Heidegger 1927/1962, Grondin 1994). Weiser used this as a core concept when laying the foundations of ubiquitous computing, and his ideal was for the systems we design to be "literally visible, effectively invisible" or, we suggest, objectively visible but subjectively invisible. As he put it in (Weiser 1994a):

A good tool is an invisible tool. By invisible, I mean that the tool does not intrude on your consciousness; you focus on the task, not the tool.

An old example from Heidegger is the way that a skilled carpenter engaged in his work focuses on the use of the hammer, and how it changes and is combined with other tools and materials, rather than focusing on the hammer in itself. Heidegger called this practically engaged and non-rationalising use 'ready-to-hand', in contrast to the rationalising, objectifying and abstracting activity he categorized as 'present-at-hand'. He saw both modes or categories of use as being set within the ongoing circular process of interpretation, in which one is influenced by one's understanding and experience of older tools and media when using any new tool or medium. One's use of the tool in the course of everyday, situated and social interaction, combining the new tool with the heterogeneous others used in everyday life, builds up new experience and understanding - that will affect how one uses and interprets another new tool. In time, this process of accommodation and appropriation lets one focus on the use of the tool, and not on the tool in itself, thus making the tool 'disappear' as Weiser later discussed.

Dourish similarly called for a move towards design of interactive systems which have a better fit with everyday human activity, understanding and interaction, and with the practically engaged and non-rationalising way that everyday activity takes place. Weiser and Dourish focus on raising our awareness of embodied interaction, i.e. the interpretation and use of a system by a user in a ready-to-hand way. However, in moving away from traditional HCI and interactive systems design, Weiser and Dourish focus almost entirely on design to support embodied or ready-to-hand interaction. They do not fully address the relationship between the two modes. In particular, how does a tool become invisible or ready-to-hand?

Heidegger, and his successors such as Gadamer and Ricoeur, held that situations where a tool becomes present-at-hand are crucial to the individual's learning and to the differences between individuals. The ongoing 'feedback loop' of interpretation and understanding integrates these two modes, and social interaction affords variation in people's understanding as well as consistency in their behaviour. For example, creativity can be considered as the variation of an individual's subjective understanding from his or her prior understanding and from others'. The individual may then be very conscious of his or her own activity, rationalising it and very aware of it, i.e. the system or tool is present-at-hand. A most important situation here is the accommodation and appropriation of a new technology into a setting or 
community of use. As pointed out in (Schmidt 1997) and in (Chalmers 2003), a system, like any formal and finite construct, necessarily involves under-specification of the situation of its use, and therefore openness to interpretation and variability of its normative effect. This allows the individual user to conform to a script-like pattern of actions, or to treat the system as flexibly interpreted, map-like resources for situated action. People accommodate the characteristic affordances of a new tool, but they may also appropriate it to suit the practices and priorities of their own contexts and communities of use i.e. other, older tools and media, and other people. With experience of its use, the tool may become understood and familiar to the individual, i.e. more ready-to-hand and embodied. Similarly, as two people perceive one another's use, with each interpreting and reacting to each other, they can achieve intersubjective consistency of behaviour-consistent with each other, but not necessarily with the use expected by the designer. A use or activity that is new and present-at-hand for one of them can thus become learned and ready-to-hand for both. The circular process of interpretation, whereby perception and activity are influenced by understanding, but also feeding into and changing understanding, thus relies on the interplay between ready-to-hand and present-at-hand interpretation.

Embodied interaction, as Dourish and Weiser made clear, is an aspect of human activity that is under-emphasised in HCI. Nevertheless, ready-to-hand embodied interaction and present-at-hand objectification are interdependent-and neither author addresses this. In simpler terms, the context of use is founded on both objective and subjective interpretation, with each influencing the other over time. We have to expect that a new technology will be to some degree present-at-hand, no matter how well the designer aims towards embodied or ready-to-hand interaction. This is most clearly the case when the technology is new, but other situations arise that neither Weiser nor Dourish fully address. One is breakdown, where the affordances of even the most familiar tool may significantly differ from those of everyday ready-to-hand use e.g. when the head of the carpenter's hammer becomes loose, so that he becomes very aware and conscious of it, and the difficulty of progressing in his task. Another example might be the breakdown that occurs with a mobile phone when it loses its network signal: one's attention may turn from a conversation 'through' the phone and its infrastructure to the tool itself. Another situation in which one can no longer work 'through' the tool in a transparent way is when the task involves deliberately focusing on the tool itself. This might happen because of prior breakdown: the carpenter may work on the hammer, to fix it, and the phone user may focus on the signal strength indicator, waiting or moving until he or she regains a signal. It also may occur as an act of conscious learning or analysis, e.g. a novice carpenter trying to improve his hammer swing, the expert game player explaining a tricky tactic to a novice, a researcher studying how a new mobile technology works in use or, as Dourish suggested, an individual user explicitly using the representation of system structure to adapt it. Another occurrence of deliberate present-at-hand use of a tool can occur when one consciously considers 
how it represents one's activity and then presents that activity to others. A fun example of this is the use of GPS logs to spell out a name on a cartographic scale, as in GPS drawing (www.gpdrawing.com), but a more common example is when one avoids a web site or a surveillance camera, or turns off an active badge, because one wants to avoid being observed by others.

The most profound technologies may be those that disappear, as Weiser said at the start of his Scientific American article, but it may be clearer now that they do not weave themselves into the fabric of our everyday life. Disappearance happens through the process of coupling and contextualization i.e. the circle of interpretation, action and experience that weaves together both ready-to-hand and present-at-hand uses of a tool by people over time. The objectifying use of tools and information is a constraint, influence and a resource for new forms of interaction, for sharing and learning, and is a precursor and foundation for 'invisible' everyday use. It seems that a degree of care has to be taken when treating embodied interaction, disappearance and invisibility as an ideal for context-aware and ubiquitous computing. No tool or system can always be invisible, and perhaps should not, as there are times when one cannot "focus on the task not the tool" because the task $i$ s the tool.

Mark Weiser suggested that even a "glass TTY UI can be ubicomp" if its use is well woven into the fabric of people's collaboration and interaction (Weiser 1994b). Again, this may seem contradictory to the common notion of ubicomp and context-aware systems, involving technologies such as location sensors, mobile displays and wireless communication, but Weiser was clear that it was not the technology in itself that made for ubicomp. Instead he suggested that we should aim for and support the accommodation and appropriation of computing into everyday life, so that its use is non-rationalized, intersubjective and interwoven with the other media that we use. What he perhaps did not fully deal with was the way that rationalized, objective and focused interaction may be necessary to the process of achieving this ideal.

If one accepts this broader view of use, coupling and contextualisation, what changes in system design principles can one assume? One issue for ubicomp designers to consider is that long-term use of their system is likely to include focused, rationalising, present-at-hand use: breakdowns, people teaching others about the system, people learning from others' use of the system, and people adapting the system. Ideally, we might make a system in which ongoing system execution - including any system adaptation - is well-coupled with use that its users never have to rationalize about it, focus on it, or explicitly approve any adaptations. Pragmatically speaking, we suggest that this is unlikely to happen. However, accepting that users will sometimes focus on and rationalize about a tool should not be taken as a reason or excuse to make a tool that they always have to focus on in order to use it at all. Instead, we suggest that systems support rationalising 
present-at-hand use in ways that feed into and aid the process of coupling and contextualization that leads to embodied interaction. We should treat system design that affords episodes of objectification of use and conscious interaction as conforming to the ideals of ubiquitous computing, rather than contrary to them-but only if the effect of those episodes is to make the system better woven into everyday life and embodied interaction.

We can use as a design example Dourish's proposal of an information space for revealing, articulating and adapting system structure and its use. We would expect that one component of such a system would be a manipulable representation of 'objective' system structure, as he suggests. However, other components seem desirable given our perspective on this kind of system. Revealing and articulating everyday activity and embodied interaction suggests that this activity and interaction is recorded, represented and made a resource for times when users focus on the system in a rationalising way. This is likely to mean more than replaying or listing all the events and actions recorded by the system in full detail. Even though the finitude of systems' sensors and representational schemes already abstract over and select from human activity, users are still likely to find that the volume of data is too high and the relevance of much of it too low. We suggest then that another component of such a system might then afford users' abstraction over and selection from the record of past activity.

As mentioned at the end of the last section with regard to the George Square system, one useful form of abstraction may be based on the temporal patterns of past use, such as clustering and correlating tracked features such as locations one has entered, web pages loaded into one's browser, and tools and devices one has used. These would afford, for example, comparing one's recent activity with what others did in similar circumstances. (Of course, one might alternatively enter or select such features to explicitly form a query.) The system could then find other past occurrences of those actions and interactions, determine who else often went to the same places, looked at the same web pages, used the same tools and devices, and so forth - and then display the record of what people did around that time e.g. what other locations, pages, tools and devices preceded, followed and were combined with each such past use within a given 'window' of time.

A general system design goal we suggest here is to interconnect objective representations of system structure with other more subjective and 'historical' representations. In each would be tools for abstraction, selection and so forth. For example, class hierarchies and database table structures might possibly be used in the first case, while clusters, selections and time windows might be useful abstractions over past use of the same system. One could concentrate on and interact with particular components or elements of system structure, and the system could highlight in a neighbouring display the patterns of past use of those selected components: where they were used, who used them, and so forth. One could 
concentrate on and interact with one or more locations or web pages, and have highlighted in a neighbouring display the elements of system structure that were used most often or most problematically in those locations and with that information. Note that focusing on the objective component could trigger the subjective component to act as a 'contextual' display, and vice versa, so that neither is primary: users could use activity in one to feed into the other and then back again.

More generally still, we suggest that system designs should support users in rationalising, focusing on and abstracting over the system 'in itself' along with its past use, so that they might adapt the system so as to better fit with their later non-rationalising ready-to-hand use, along with the other people and other media that make up their everyday activity. We suggest that playback of recordings or logs of activity in a 'raw' state will not, in itself, meet these ideals. For example, Adobe Photoshop is a powerful tool, which many designers use as a core resource for their work. It can be set to record every action one does in it, which allows some undo operations. Also, however, one can save one's history to a file and save it for later reuse, or send such a file to a friend or colleague so as to share design techniques and examples. Only Photoshop activity is recorded, and not the other tools used, the locations of use, the documents, project briefs and other colleagues involved and so on. Also, the tools for working with that data do not afford searching for relevant log files or subsections of logs, for people who have used a particular function or operation, aggregating and clustering patterns of use and so forth. Most significant of all, however, there is no way to use this information on past use to change Photoshop's deep system structure, for example by importing a software component that other people found useful, but which one does not yet have installed, on the basis of exploring information on what the module was used on, who used it and what its effects were i.e. on the basis of the user's understanding of prior contexts of use by other people, as well as any objective or functional description of the component.

In summary, we suggest a pragmatic response to the inevitability and importance of present-at-hand use, informed by the previous section's discussion of the significance of the past in context and contextualization, and this section's discussion of the interdependence of objective and subjective modes of interpretation. We suggest that present-at-hand use can make the tool better woven into longer-term ready-to-hand embodied interaction, and that temporal patterns of embodied interaction can feed into and are resources for present-at-hand use.

\section{Conclusion}

This paper has examined a number of the ideals and origins of context-aware and ubiquitous computing, looking especially at the effect on one's ongoing activity of the past. One's experience and understanding of social interaction and ways to 
interweave heterogeneous media are important resources for using and interpreting the people, systems and artifacts currently at hand.

By going back to the theoretical roots of several key pieces of research work, in sociology and philosophy, we were able to look at later critiques, advances and alternatives in those fields. This led to a reassessment of the notion of invisibility or disappearance that often characterises ubiquitous computing, in particular the way that more present-at-hand and 'visible' interaction is essential to the process of a tool or system becoming ready-to-hand, invisible and contextualized within a user's activity. Similarly, we consider occasional shifts out of the ready-to-hand mode of interpretation as not only inevitable but also vital to building up experience and understanding.

Given such a theoretical standpoint, a number of consequences for system design arise. It seems more difficult to accept Weiser's ideal of 'invisible' technology as an achievable ideal, as we have to accept that a system will be, and should be, used in an more ready-to-hand way occasionally. Our suggested response is to better interconnect the systems or system components that handle these different modes of activity, for example by tracking ready-to-hand activity and making it a resource for users and developers when they work in a more focused present-at-hand way, so as to help them understand and adapt system behaviour, and thus feed back into improved ready-to-hand use.

More generally, we see significant potential in making more use of the past in context-aware systems design, for example through subsystems such as recommenders, maps of the availability of infrastructure, helpful demonstrations of what people did in similar circumstances to one's own, QoS management, prefetching and, potentially, system adaptation. We intend to explore such design possibilities in our research, with the overall intention of design practice and theory that are in accord with each other, and in accord with people's use and interpretation.

\section{References}

Abowd, G., Mynatt, E., and Rodden, T. (2002): The Human Experience, IEEE Pervasive Computing, Jan-Mar, 48-57.

Bannon, L. \& S. Bødker (1997): Constructing Common Information Spaces, Proc. Euro. Conf. Computer Supported Cooperative Work, Lancaster, pp. 81-96.

Bardram, J. (1997): Plans as Situated Action: An Activity Theory Approach to Workflow Systems. Proc. Euro. Conf. Computer Supported Cooperative Work, Lancaster, pp. 17-32.

Bardram, J., Kjær, R. \& Pedersen M. (2003): Context-Aware User Authentication-Supporting Proximity-Based Login in Pervasive Computing, Proc. Ubicomp 2003, Seattle, 2003, pp. 107-123.

Bowers, J et al. (1995): Workflow from Within and Without: Technology and Cooperative Work on the Print Industry Shopfloor, Proc. Euro. Conf. on Computer Supported Cooperative Work (ECSCW), 51-66 1995. 
Brown, B. et al. (2003): Lessons from the Lighthouse: Collaboration in a Shared Mixed Reality System. Proc ACM CHI 2003, pp. 577-584.

Brown, B. \& M. Chalmers (2003): Tourism and Mobile Technology, Proc. Euro. Conf. Computer Supported Cooperative Work (ECSCW 2003), Helsinki, pp. 335-354.

Chalmers, M. et al. (1998): The Order of Things: Activity-Centred Information Access, Proc. WWW7, Brisbane, published as Computer Networks and ISDN Systems, 30, pp. 359-367

Chalmers, M. (1999): Comparing Information Access Approaches, Journal of the American Society for Information Science, 50th Anniversary Issue, vol. 50(12), pp. 1108-1118.

Chalmers, M. et al. (2003): Seamful Design: Showing the Seams in Wearable Computing, Proc. IEE Eurowearable, Birmingham, pp. 11-17.

Chalmers M. (2003): Awareness, Representation and Interpretation, Computer Supported Cooperative Work 11:389-409.

Christensen, H., \& J. Bardram (2002): Supporting Human Activities-Exploring ActivityCentered Computing, Proc. Ubicomp 2002, Göteborg, pp. 107-116.

Dey, A., G. Abowd \& D. Salber, (2001): A conceptual framework and a toolkit for supporting the rapid prototyping of context-aware applications, Human Computer Interaction, pp. 97-167.

Dourish, P. (1995): Developing a Reflective Model of Collaborative Systems, ACM Trans. CHI, 2(1), 40-63.

Dourish, P. (2001): Where the Action Is: The Foundations of Embodied Interaction. MIT Press.

Dourish, P. (2004): What We Talk About When We Talk About Context, to appear in Personal and Ubiquitous Computing.

Fleck, M. et al. (2002): Rememberer: A Tool for Capturing Museum Visits, Proc. Ubicomp 2002, pp. 48-55, 2002.

Gadamer, H.-G., (1989) Truth and Method, 2nd edn., trans. J. Weinsheimer \& D. Marshall, Crossroad. (Original published in 1960.)

Garfinkel, H. (1967): Studies in Ethnomethodology. Prentice Hall.

Garlan, D. et al. (2002): Project Aura: Toward Distraction-Free Pervasive Computing, IEEE Pervasive Computing, April-June 2002, pp. 22-31.

Giddens, The Constitution of Society, Polity Press, 1984.

Giddens, A. (1995): Garfinkel, Ethnomethodology and Hermeneutics, Politics, Sociology and Social Theory: Encounters with Classical and Contemporary Social Thought, Stanford University Press, 233-245.

Goldberg, D., et al. (1992) 'Using Collaborative Filtering to Weave an Information Tapestry', Comm. ACM 35(12), 61-70.

Greenhalgh, C. et al. (1998): Predicting network traffic for collaborative virtual environments, Computer Networks and ISDN Systems, 30:16-18, pp. 1677-1685.

Grondin, J. (1994): Introduction to Philosophical Hermeneutics, trans. J. Weinsheimer, Yale University Press.

Heidegger, M. (1962): Being and Time, Harper \& Row. (Original published in 1927.)

Holmquist, L.E. et al. (2001): Smart-Its Friends: A Technique for Users to Easily Establish Connections between Smart Artefacts. Proc. Ubicomp 2001, Atlanta, 116-122.

LaMarca, A., et al. (1999): Taking the Work out of Workflow: Mechanisms for Document-Centred Collaboration, Proc. Euro. Conf. on Computer Supported Cooperative Work, Copenhagen.

Merleau-Ponty, M (2002): Phenomenology of Perception, $2^{\text {nd }}$ edn., Routledge. (Original published in 1945).

Nardi B. (ed.) (1996): Context and Consciousness: Activity Theory and Human-Computer Interaction, MIT Press.

Nöth W. (1995): Handbook of Semiotics. Indiana University Press. 
Oppermann R. et al. (1999): Hippie: A Nomadic Information System, Proc Handheld \& Ubiquitous Computing (HUC), pp. 330-333.

Resnick, P. \& Varian, H. (eds.) (1997): Communications of the ACM, special issue on Recommender Systems, 40(3).

Ricoeur, P. (1981): Hermeneutics and Human Sciences: Essays on Language, Action, and Interpretation, trans. J. Thompson, Cambridge University Press.

Schutz, A. (1967): Phenomenology of the Social World, trans. G. Walsh \& G. Lehnert, Northwestern University Press. (Original published in 1932.)

de Saussure, F. (1983): Course in General Linguistics, trans. Wade Baskin, McGraw-Hill. (Original published in 1906.)

Schiele B., Jebara T. \& Oliver N. (2001): Sensory-Augmented Computing: Wearing the Museum's Guide, IEEE Micro, 21(3): 44-52.

Schmidt, K. (1997): Of Maps and Scripts: The Status of Formal Constructs in Cooperative Work, Proc. ACM Group 97, Phoenix, pp. 138-147.

Signer, B., A. Erni \& M. Norrie (200): A Personal Assistant for Web Database Caching, Proc. Conf. Advanced Information Systems Engineering (CAiSE'00), Stockholm, pp. 6478.

Suchman, L. (1987): Plans and Situated Actions: The Problem of Human Machine Communication, Cambridge University Press.

Warnke, G. (1987) Gadamer: Hermeneutics, Tradition and Reason, Stanford University Press.

Weiser, M. (1991): The Computer for the Twenty-First Century, Scientific American, 94-110, Sept. 1991.

Weiser, M. (1994a): The world is not a desktop. Interactions; January 1994; pp. 7-8. ACM Press.

Weiser M. (1994b): Creating the invisible interface: (invited talk). ACM Conf on User Interface Software and Technology (UIST94), p.1.

Wilson, T. (1983): Qualitative "versus" quantitative methods in social research, Department of Sociology, University of California at Santa Barbara, 1983 (mimeo); published in German in the Kölner Zeitschrift fur Sociologie und Sozialpsychologie, vol. 34, 1982.

Winograd, T. \& F. Flores (1986): Understanding Computers and Cognition, Addison Wesley.

Wittgenstein, L. (1958): Philosophical Investigations (3rd ed.). Trans. G.E.M. Anscombe, Oxford University Press. 